\title{
Insight
}

\section{Contemporary Visions of Progress in Ecology and Thoughts for the Future}

\author{
$\underline{\text { Brian M. Starzomski }}^{1}, \underline{\text { Bradley J. Cardinale }^{2}}, \underline{\text { Jennifer A. Dunne }}{ }^{3}$, Melinda J. Hillery $^{4}$, Carrie A. Holt $^{5}, \underline{\text { Meg A. }}$ \\ $\underline{\text { Krawchuk }}^{6}, \underline{\text { Melissa Lage }}^{7}, \underline{\text { Sean McMahon }}^{8}$, and Michael C. Melnychuk ${ }^{9}$
}

\begin{abstract}
Although ecological research is progressing rapidly, the answers to certain key questions continue to elude us. This paper considers several of the contemporary challenges facing ecology. (1) Terminology is voluminous and often poorly defined, resulting in inefficient communication. (2) The concept of scale affects our inferences about system structure and function, requiring us to continue an almost heuristic investigation of breaks, domains, and integration. New tools that more explicitly incorporate scalar issues will need to be developed for progress to take place in the field of ecology. (3) Increasingly, it is expected that applied questions will be solved in less than a year. This demand for solutions from ecologists often produces short-term and inadequate responses. (4) How can ecologists improve communication between subdisciplines, with undergraduate students, and with the public? How will ecology be done in the future, and by whom? We provide some background to these observations and questions, and offer some potential solutions from the viewpoint of young practicing ecologists.
\end{abstract}

\section{INTRODUCTION}

Ecology has gone through many changes since its beginnings in natural history, from which it has evolved into rigorous modern observational, experimental, and theoretical analyses of patterns and process (McIntosh 1985, Real and Brown 1991). When asked to provide insight into the global environmental crisis, ecology spawned new subdisciplines such as conservation biology (Soulé and Kohm 1989, Soulé and Orians 2001) and restoration ecology (Dobson et al. 1997). Although the increasing demand for ecological research bodes well for those who practice the discipline, the demand for environmental solutions outweighs the ability of ecologists to produce them. Further, there have been several unflattering analyses of the foundations of ecology (Sagoff 1985, Peters 1991, O'Connor 2000, but see Shurin et al. 2001 for a rebuttal). What are we to think of the critiques of our science, and more importantly, how are we to develop our understanding of natural systems?
Ecology exhibits periods of explosive growth and relative stasis as interest in various subdisciplines waxes and wanes over time (McIntosh 1985, Real and Brown 1991). Holling (1998) and Harte (2002) represent two recent examples of explicit calls for shifts in dominant modes of thinking, including changing fundamental properties of the way in which ecologists do science. This series of shifts in the dominant ways of thinking is not restricted to ecology (for an insightful review, see Graham et al. 2002) but is characteristic of many sciences (Kuhn 1962). These paradigm shifts emphasize that we must continue to learn about ecology as well as how to be ecologists.

On the heels of our predecessors, we young researchers and managers will make important contributions and changes to ecology in the coming decades. A concrete understanding of the problems we face in ecology is important to defining the goals of our science. Seminars and courses in graduate schools provide fertile ground for discussing these topics. These discussions typically involve both senior researchers and young scholars, although they seldom move beyond the discussion forum

\footnotetext{
${ }^{1}$ University of British Columbia; ${ }^{2}$ Department of Zoology, University of Wisconsin-Madison; ${ }^{3}$ Santa Fe Institute; ${ }^{4}$ Centre for Ecosystem Management, Edith Cowan University; ${ }^{5}$ School of Resource and Environmental Management, Simon Fraser University; ${ }^{6}$ Department of Renewable Resources, University of Alberta; ${ }^{7}$ Department of Ecology and Evolutionary Biology, Brown University; ${ }^{8}$ Complex Systems Group, Ecology and Evolutionary Biology, University of Tennessee; ${ }^{9}$ Fisheries Centre, Department of Zoology, University of British Columbia
} 
to the literature (but see Peterson et al. 1997 and Shurin et al. 2001). This Young Scholars' Dialogue was proposed to the editorial board of Ecology and Society in the winter of 2002 as a means of bringing some of these ideas to the forefront. By the first month of 2003, the managing editors of Ecology and Society had arranged an online portal at the Resilience Alliance that authors could use to post and discuss questions and ideas. More than 300 pages of posts were distilled into the present paper after three months of discussion. The authors are all young researchers completing their graduate or postdoctoral studies. Some of the authors work in multidisciplinary groups that aim to integrate ecological, social, and economic theory; others use micro- and mesocosm experiments to look for general rules of structure in communities. Still others explore macroecological patterns and mechanisms. The members of the group range from those working on "pure" research questions with little direct insight for conservation per se to those working as applied ecologists. As graduate students and post-doctoral researchers, we provide a synthesis of opinion for both senior and junior members of the ecological community (in the academic sense!) intended to provoke discussion and thought on the emerging direction of ecology in the 21st century. In this paper, we discuss and explore:

1. problems with terminology that impede progress,

2. scaling issues that plague our inferences,

3. applied and predictive ecology, and

4. the future of ecology in light of new quantitative methods, the diversity of researchers, and the areas in which ecology needs to make progress.

We echo the statement of Graham et al. (2002) in the introduction to a recent special feature in the journal Ecology: we are presenting these opinions as active participants in ecological research, rather than as expert philosophers of science. Input from readers of Ecology and Society [Erratum] is encouraged and can be added by following this link: Ecology and Society Discussion Page.

\section{TERMINOLOGY: CONFUSION OR CLARIFICATION?}

There is general agreement that ecology has a terminology problem. For example, Shrader-Frechette and McCoy (1993) emphasize that there are an abundance of similar but nonidentical definitions for fundamental concepts such as "stability," "community," and "ecosystem" taught in undergraduate ecology. This imprecise terminology has been repeatedly recognized as contributing to the misunderstandings that occur within and outside of ecology (Peters 1991, Shrader-Frechette and McCoy 1993, Mikkelson 1997). Often, ecologists do not know if the confusion in their work is the result of misunderstanding the terminology involved or the research itself. A recent review of the meaning and use of "connectivity" (Tischendorf and Fahrig 2000) provides an excellent illustration of an attempt to rectify the ambiguous use of a term that was causing confusion within the discipline of landscape ecology. It is clear that terminology problems hurt our science.

We have noted that the terms that tend to be the most problematic often share the following characteristics: (1) they are not mathematically defined, although we note that this is not always possible or desirable, and (2) they involve the interactions of several individuals, e.g., population ecology and more complex scales of organization.

We support the explicit clarification of terminology by urging researchers to do the following:

1. Include in all papers a section that contains definitions of terms, with references, similar to the terminological boxes used in the journal Trends in Ecology and Evolution.

2. Develop an on-line searchable database of terminology to which everyone can donate terms. The terms submitted for inclusion would be subject to a rigorous peer review process before they were finally accepted by the research community. Multiple definitions could be supported when they are significantly different, and referenced to the author when used.

3. Encourage leading journals to have a section on definitions that focuses on a detailed review of terminology and makes recommendations related to ecological concepts and definitions.

These solutions would create easily accessible and upto-date compendia of ecological terms. Making it easy to find terms that an author is introducing or using in his or her manuscript would benefit both authors and readers. 


\section{SCALE, GLORIOUS SCALE!}

Scale has long been recognized as important in ecology (MacArthur and Levins 1964, Wiens 1989, Levin 1992), and it remains a sort of "final frontier" (Kareiva 1994). Scale can be considered through time, space, taxonomy, and discipline. Because ecology is a science of scale, practitioners continue to struggle to both incorporate scalar intricacy into their research and interpret their research with respect to scale.

Experimental science in general and ecology in particular are, by their very nature, scaling. Every statistical inference essentially takes observations on the scale of the sample and generalizes them to that of the population. We are further pressed to generalize the patterns inferred for one population to others. Complex ecological phenomena may not be cleanly assigned to a small number of categories, but are thought to represent a continuum of space and time. This begs the question of whether there is a single best scale at which to conduct our experiments or couch our theory. Intuitively, many would say that there is not, but pragmatically we are always forced to narrow our focus. Below, we use time as an example to illustrate some scale conundrums.

Strayer et al. (1986) and Likens (1989) suggest that long-term studies are necessary for understanding ecological phenomena that:

1. occur slowly or infrequently in time;

2. exhibit such high temporal variability that long-term trends are required to observe patterns;

3. are interdependent and cumulative, so that historical events constrain future possibilities; and

4. exhibit time lags.

However, the definition of "long-term" used in studies is itself quite varied. In fact, ecologist have distinguished short- from long-term study in relation to at least seven different factors:

1. the natural temporal variation of a process, e.g., the time span encompassing a given confidence interval of observations of the dependent variable (Walters 1986, Carpenter 1988, Franklin 1989);

2. the life-span or reproductive cycle of the organism of interest;
3. the cycling time of the process, e.g., the turnover period of a nutrient, prey item, water molecule, etc. (Franklin 1989);

4. the successional period of a community, i.e., the time it takes the study system to reach some "steady state" following a perturbation;

5. the return interval of rare or episodic events such as disturbances (Franklin 1989);

6. the time lag between an ecological cause and its effect (Magnuson 1990); and

7. a distinct time period, e.g., long-term is $>5$ years (Likens 1992).

Because most ecological processes of general scientific and societal concern span a continuum of time, no single definition of "long-term" is sufficient for research. The above list illustrates the need for a clearer definition of a study's time and space to encourage rigor and flexibility in any application beyond its domain. It could also be argued that the world is dominated by small organisms that spend their short lives in small spaces processing materials quickly. As such, their long term is our short term when it comes to relative temporal cycles. If we continue to make progress in understanding what drives these systems (e.g., Srivastava and Lawton 1998, Lawton 1999, Mora et al. 2003), the hope is that these driving factors may be generalized toward universal ecological structures and organizing principles within and among communities (Lawton 1999). An intriguing possibility is the conceptual framework of the "temporal sliding scale." Holling (1992, see also Holling and Allen 2002) suggests that the "temporal and geometric properties [of a system] were distributed in a lumpy, or discontinuous, manner [such that] the frequency of occurrence of attributes in time and space were clustered into a small number of categories along an axis of increasing magnitude of scale in space and time." If this is the case, ecological research may need to focus more on determining what these frequencies are, and the rules that govern them. These frequencies could be focal scales of research. Studies that use small, contained ecosystems such as phytotelmata (e.g., Pitcher plants, bromeliad tanks) or moss patches might quickly produce results concerning these scale lumps.

Although long-term studies often produce very important results, e.g. the impacts of drought on the recovery of lakes from acidification (Yan et al. 1996)), we do not think that it is justifiable to suggest that ecological phenomena are best described by long-term studies, with short-term research as second-best. There are clearly benefits to short-term ecological research 
compared with long-term studies. For example, shortterm studies (1) are generally less costly and easier to complete, so that progress is more rapid as results are communicated and used quickly, and (2) inherently lend themselves to experimental manipulation and control. Thus, results and/or causal pathways are often less ambiguous than in long-term studies.

It thus follows that short-term studies are generally more efficient, giving greater knowledge per dollar or unit effort. Unfortunately, this is not always the case, and we wish to argue that both short- and long-term research is important in the development of understanding. It seems that the solution to the multiscale dilemma may lie in our ability to assess and incorporate information across various scales rather than to collapse information into a single "most appropriate" scale.

Advances in statistical and computational methods are providing frameworks that allow researchers to consider multiple scales at the same time when analyzing data. For example, in the last decade there have been important developments with hierarchical linear models and generalized linear mixed models. This family of models enables explicit declaration of correlation structures in the data that are inherent to multiscale designs (Raudenbush and Bryk 2002, Krawchuk and Taylor 2003) within the flexibility of the generalized linear model framework (McCullagh and Nelder 1989). Even more complex methods are being developed to assess correlations in time and space through the use of Bayesian Markov-chain Monte Carlo methods, e.g., BUGS. Generalized estimating equations/functions also fall into this category.

Some of the most exciting analytical methods to arise in recent years explore scale independence in systems. Network theory, which explores the generalities among and particularities within biotic and abiotic networks (Strogatz 2001), has provided new ways to describe scale-dependent and scale-invariant patterns and processes in food webs and pollination networks (Dunne et al. 2002a, Jordano et al. 2003), as well as ways of exploring the relationship between community structure and robustness (Dunne et al. 2002b). Harte and Kinzig (1997) and Ritchie and Olff (1999) have used fractal indices to characterize environmental heterogeneity and to express scale-invariant ecological patterns mathematically.

\section{APPLIED AND PREDICTIVE ECOLOGY}

The field of applied ecology includes research that addresses issues in conservation biology, the extraction of natural resources, environmental pollution, the effects of climate change on the biotic world, and the management of habitats and species. Applied ecology often acts as an interface between the scientific and academic worlds and the larger worlds of business, government, and the public. Thus, one of the fundamental challenges in applied ecology is to outline predicted outcomes and trade-offs of possible policy actions that managers must negotiate among diverse interest groups.

Predictions drawn from research in applied ecology play an important role in identifying suitable and successful management actions. Applied ecology thus needs to make reliable predictions as well as gain a functional understanding of system mechanisms. However, when addressing applied questions, there are at least two potential problems with regard to obtaining a detailed understanding of system mechanisms. In many cases it may be necessary to take action before an in-depth understanding has been achieved. Mechanisms take a long time to unravel, and answers to applied questions are generally needed before the system can be fully understood. However, an improved understanding of the mechanisms that drive particular phenomena will not necessarily lead to improved predictions about them. One example of this are the chaotic dynamics that emerge from slight differences in the initial conditions of a system. Because we can never measure those initial conditions precisely, we cannot necessarily predict the trajectory the system will take.

As an alternative, it is possible to make reasonably accurate predictions with little understanding of mechanisms because many patterns repeat themselves. We can often come up with an answer, i.e., a predicted pattern or response, to applied questions before we really understand the processes behind them. This is only sufficient when the most important thing is an "answer," and not the understanding. This is often the case with short-term management actions. By taking action early rather than further studying the mechanisms, we can use the action as an experimental manipulation to unravel the operating mechanisms in the system (Walters 1986). When management decisions are made, we should take full advantage of the situation to test hypotheses. Ecologists and managers should be more explicit in 
thinking through the potential outcomes of these actions, organizing these "perturbations" to test multiple hypotheses whenever possible, and learning from their actions. This leads to a reliance on adaptive management programs.

Prediction, of course, is not always possible. Limitations include the fact that:

1. ecological systems do not remain stationary, and even long-term data do not guarantee that short-term predictions will hold (Hellmann et al. 2003);

2. predictive ability generally decreases with projection time. Predictions become less reliable over longer time periods because of the compounding effects of small errors;

3 . there are trade-offs between accuracy/detail and robustness/generality. In contrast to more detailed models, simpler models may forecast less accurate predictions in the short term, but might be a better predictor of general behavior in the long term (Hilborn and Walters 1992); and

4. the magnitude of impacts on a system is frequently misunderstood. Unless we apply treatments ourselves, we may have a poor knowledge of the experimental manipulations from which we try to assess effects.

In making predictions, we should explicitly outline the time frame over which we expect our predictions to hold. We must be clear about what our predictions cannot do. Continually updating these predictions with new information may extend their reliability as well as increase their accuracy. For example, a Canadian Forest Service model for forecasting human-caused forest fires uses a Bayesian framework and updates the model by including "prior" information from recent events, in addition to longer-term relationships with historical data (Todd and Kourtz 1991).

All predictions for ecological management are uncertain to some degree, and this uncertainty affects how this information can be used by managers. Ecologists are learning to deal more efficiently with this prediction uncertainty. For example, fisheries ecologists historically presented managers with a number that represented the allowable catch or the level of fishing mortality. Because these numbers did not allow for the evaluation of alternatives, the managers receiving them had few options. Advice to managers now generally includes probability distributions of expected outcomes and levels of risk for possible policy actions, thereby incorporating uncertainty. These data present a more informative base on which decisions can be made. This incorporation of uncertainty allows managers to react to a "surprise" in system response, a "safe-fail" rather than "fail-safe" methodology (Peterson et al. 1997). Because models can never predict the effect of management with $100 \%$ accuracy, potential management actions should be evaluated in simulation models according to various future scenarios. The best management action can be chosen based on which is the most robust to these uncertainties (de la Mare 1998, Sainsbury et al. 2000).

One of the biggest obstacles to incorporating uncertainties into management is the fact that scientists, managers, and the public do not clearly understand the term "uncertainty." This hinders the effective use of scientific uncertainty in management decisions. The third assessment report on climate change from the Intergovernmental Panel on Climate Change (IPCC 2001) illustrates a clear bridging of this communication gap, although some parties have chosen to ignore it. This report is written for policy makers, and the clear language reflects the nonscientific audience. Terms of scientific uncertainty have been converted into simple phrases ranging from " $X$ is very unlikely to occur," to " $X$ is probable," to " $X$ will very likely occur." In addition, "scenarios" are used to illustrate the range of possible outcomes so that uncertainty is built into the figures. Further, the panel has mechanisms in place to avoid inaction, often citing "collective judgment" or "best guess" when a scientific consensus is obviously not a possibility. We would like to see more studies that explicitly incorporate this type of uncertainty into their management advice, so that we can communicate our best guesses for questions of applied importance.

\section{NEW QUANTITATIVE METHODS IN ECOLOGY}

Almost every element of scientific inference is the result of "testing a hypothesis," no matter what the scale of the question. Although we can creatively theorize around complexities and hypotheses, we need to improve our ability to articulate these ideas through data and analysis. We suggest that a stronger educational focus on statistical techniques would be very valuable in advancing our understanding of ecological systems.

Often, students drawn to our field have little interest in statistics. Nevertheless, this must become a core 
element of our education as ecologists. The basic requirement for all ecologists must include a good course in basic statistical methods (many of us have sampled ineffective statistics courses), preferably with an ecological focus, and one or more electives in any other statistics class. This acknowledges that ecologists have very different foci, and not all have time to become experts in the intricacies of statistics.

For students with a more analytical bent, the introduction to a spectrum of alternative current methods in statistics is necessary. A showcase of methods in the form of a reading group that provides a brief but thorough familiarization can be valuable. For those students with the mathematical skill to really get into the foundations of new techniques, expectations are high to popularize methods within the broader ecological community. Although many universities already provide one or more formal courses in ecological statistics, active discussion groups that focus on statistical issues in ecology are lacking in many institutions. We believe that this latter element is critical. One important benefit of a more thorough understanding of statistics is a reduction in the number of errors made in data analysis by ecologists, such as the adoption of inappropriate methods, assumptions, and interpretations. Although this has always been a problem in ecology, it may be exacerbated by the abundant "point-and-click" statistics packages currently available that allow users to ignore important assumptions. Correcting this may help increase our understanding of ecological systems by providing more accurate quantification of the ecological data from which we make our inferences.

More room for model uncertainty in statistical assessment is also needed, to allow the reader of a paper to interpret the results with the author. In the classical, frequentist approach, this amounts to giving the reader enough information to make an independent assessment, which includes, but is not limited to, providing a family of models, not only the single most significant model as suggested by the touted alpha.

We believe that encouraging the expanded use of meta-analysis may be important both in developing and testing theory and in advancing ecology. Numerous data sets exist that could be profitably analyzed for new ecological understanding and would complement our experimental and theoretical research programs. This relies on something that ecologists are generally not very good at: sharing their data.
Ecologists must become better at this. Programs are being developed to further facilitate data sharing, e.g., SEEK Ecoinformatics .

Finally, we do not imply that there will be any specific statistical methods that will push ecology forward. Rather, it is the mind-set and level of understanding under which we assess data and models that will be paramount. Although the continuous development in analytic techniques opens new doors, simpler traditional techniques complement complex and recently developed methods. We predict much progress in ecology associated with our relatively simple suggestion that we improve our statistical literacy.

\section{WHO ARE THE RESEARCHERS OF THE FUTURE?}

As ecology prepares itself for the challenges that it will face in a century characterized by intense human impacts on the environment, these questions are worth asking: Who are the researchers of the future? What characteristics will they have?

\section{Geographic diversity}

Most practitioners of ecology are Western white males. The lack of widespread geographic representation among ecologists is likely to continue unless there is financial support either from home governments, international institutions, or sympathetic wealthy countries. Environmental crises will play an important and unfortunate role in increasing the geographic diversity among ecologists: there are likely to be continued upswings in trained ecologists and research funds in countries that face immediate and economically relevant environmental crises.

\section{Training diversity}

Most people who currently do ecological research were trained as ecologists. Collaborations between ecologists and other scientists have been very profitable. Disciplines represented include physics, applied mathematics, computer science, economics, demography, and quantitative sociology. Currently, we see many cross-boundary research programs that successfully combine the expertise of ecologists and physicists (West et al. 1997), ecologists and economists (Carpenter et al. 1999), and others. We advocate that increased funding be made available for these cross-discipline collaborations. 
Further to this point, we would like to see more students, or ecologists-in-training, involved in applied ecology work. There is an unfortunate resistance to such an approach in applied ecology where government agencies and other bureaucracies are the primary directors, e.g., conferences of invited speakers only, or conference costs inaccessible to students. This will require a more concerted effort for communication between government agencies and universities.

\section{Racial diversity}

The inadequate representation of racial minorities in ecology stems from many things, including the lack of role models/mentors, poor high school science education, a desire to pursue more lucrative academic paths such as biotechnology, and problems with fitting into the dominant academic culture. A few necessary improvements include better high school and college education and outreach, a greater geographic representation of ecologists from non-Western countries, and active recruitment and retention of minority candidates into faculty and role model positions. Further, programs encouraging interchanges of ecologists between Western and non-Western countries may be important. Investment by richer nations in training more ecologists in less economically robust countries is needed.

\section{Gender diversity}

Although women are well represented at pre-doctoral levels, there are fewer of them at the post-doc level and beyond. Some of this may be explained by strong lifestyle and cultural barriers, e.g., the issue of effectively having to choose between becoming a top scientist or having children. We believe that more should be done to encourage women to pursue careers in ecology; one way is to increase the number of career options as outlined below.

\section{Lifestyle diversity}

Only a few paths are currently available for Ph.D.s in ecology. These include full-time faculty positions, consulting, government jobs, and NGO work. There is a lack of flexibility in possible career choices for ecologists both within and outside of academia. This is a major contributor to the drop-out syndrome among women. For ecology to thrive in the future there will need to be greater development, support, and acceptance of unconventional career paths.
Finally, we believe the future of ecology lies in the collaborative efforts that will be required to address complex environmental problems that cross disciplinary and system-specific boundaries. As a consequence, those poised to make some of the greatest contributions are people who are broadly trained and who have the skills to interact outside of their particular realms of knowledge. This will require many graduate programs and post-doc opportunities to increase the diversity of curricula and research experiences. Excellent examples of such programs currently exist, e.g., the Graduate Program in Regional Resilience and Adaptation at the University of AlaskaFairbanks and the Santa Fe Institute, although more are needed. We also believe that young ecologists should prepare by routinely incorporating literature from outside of ecology as part of their normal reading and be prepared to actively engage in cross-discipline research environments.

\section{THE PRESENT AND FUTURE OF ECOLOGY}

Ecology will continue to play a major role in the use of theory and data to provide insight into specific and wideranging environmental problems. Current examples include the introduction of adaptive management (Holling 1978, Walters 1986), population-specific management designs such as reports from the Committee on the Status of Endangered Wildlife in Canada and the Environmental Protection Agency, and the broad linking of social, economic, and ecological systems (e.g., Berkes and Folke 1998, Costanza et al. 1996, Perrings et al. 1995). The fact that the word "ecology" has been coopted by the environmental movement may decrease our ability to seem objective to the public and to policy makers (Westoby 1997). We may also engage in very academic debates that lose sight of the conservation values of research, e.g., in biodiversity-ecosystem function (Srivastava 2002). These should not slow our drive to find the processes underlying patterns in the natural world, nor should it decrease our ability to contribute to the solution of important applied problems.

The amount of available information continues to increase, and ecologists are constantly presented with new opportunities and methods for sharing, analyzing, and collecting data. In particular, the rapid advances in computer technology are causing enormous changes, not only in the field of ecology but also in science in general. Current popular and important research areas using these advances include network theory (Albert et al. 2000, 
Strogatz 2001, Dunne et al. 2002a,b); the resilience, robustness, and stability of ecosystems (Walker et al. 2002); ecoinformatics, e.g., SEEK Ecoinformatics; species/system response to climate change (Parmesan and Yohe 2003, Root et al. 2003), and macroecology (Brown 1995, Williams and Martinez 2000, Harte et al. 2001). Landsat and other remote sensing technologies are being used to understand large-scale patterns and spatial relationships between components of the landscape (Turner et al. 2001, Bawa et al. 2002). Easy access to these new sources of information enables a wider array of researchers to make progress in ecology, and we reiterate our belief that rapid development of online databases would be extremely valuable in sharing data for new discoveries.

Cross-boundary research is also becoming increasingly important in ecology. The term "cross-boundary" pertains not only to boundaries between disciplines but also to other obstacles that prevent the integration of research, e.g., cultures, languages. An example of this is found in the literature on resilience and adaptive cycles. This theory is rooted in social as well as ecological systems, making cross-boundary work essential (Gunderson and Holling 2002).

Intense, focused communication and discussion are crucial for cross-boundary research. Small working groups may provide the best means of focusing research efforts in cross-boundary collaborations, which will result in improved communication among disciplines. At least some of the progress of these projects must be measured in the success of achieving cross-boundary dialogue, regardless of the outcome. For example, attempts to analyze and manage for socio-ecological resilience and/or specific environmental issues are often challenged by different groups, hence the emphasis on participatory processes in this area (e.g., Walker et al. 2002). As important as the structure of cross-boundary research are the people involved, who must be willing to abstract the ideas in their disciplines from the details, question their assumptions, and seek inconsistencies among fields. These integrative skills can be developed over time. They should be emphasized in the education of our young scientists, both undergraduates and graduates (Holling 1998, Gass 2002), and will also aid in our ability to communicate our science to the public.

Ecosystem restoration and mitigation, already important, are likely to become more so. We believe that the best complement to continued progress in restoration ecology will be research on how ecosystems adapt to ongoing anthropogenic disturbances and how these disturbances affect ecosystem goods and services. This is the current research agenda in freshwater lake studies: not to return these bodies of water to predisturbance levels, but rather to predict how changes will occur in response to inevitable climate change and what this will mean for fisheries and water quality (Carpenter et al. 1999). Ecological restoration and mitigation must incorporate more ecological theory and empirical results into its practice, because it is currently doing a very poor job of this. The highly litigious nature of our society will make mitigation of environmental impacts commonplace, and there will be an increasing need for good science to inform these efforts.

We need continued progress in:

1. community assembly rules. Are communities random or nonrandom associations of taxa, and are there rules that govern how communities assemble?

2. alternative stable states. Are human impacts reversible or irreversible? Can a system that might alternate between multiple states be shifted back to the state it was in prior to the disturbance?

3. community structure vs. function. Which is more sensitive to human impacts, and which is the better measure of a "natural" system?

4. local vs. regional controls on species characteristics such as abundance, occurrence, and coexistence. What is the relative importance of the within-habitat vs. the between-habitat processes that affect these characteristics?

5. the role and structure of species invasions. How do species invasions affect the ecosystems they become part of? What makes a species a good invader? What makes an ecosystem open to invasion? What potential niches are widely invasible?

6. ecological economics. Placing an economic value on nature's services will likely increase public recognition of the need to protect resources.

Ecologists must better communicate their findings and understanding of ecosystem structure and function to the public while walking a fine line between communication and advocacy. We are doing research 
as important and novel as that being carried out in any other field; one charismatic breakthrough may be all that is needed to elevate the status of ecological research in the eyes of the public. Ecology is ripe for this breakthrough. We strongly urge ecologists to enhance their skills for communicating with the public and other researchers.

\section{CONCLUSIONS}

For ecology to progress, it must incorporate both its scientific foundations and the ability to develop and integrate novel methods and ideas into ecological theory and research. Only by cultivating both approaches will ecologists be able to address the critical questions the field faces. We have discussed a number of current problems in ecological research and made an attempt at some simple solutions. We are optimistic about the future of ecology despite the problems we outline. We fully expect, over the course of our careers, to make great gains in understanding how nature works. There is no shortage of interesting questions to tackle, and, as young scholars, we have provided a modest framework for how some improvements in our science might help to make these explorations more efficient and more effective.

Responses to this article can be read online at: http://www.ecologyandsociety.org/vol9/iss1/art14/responses/i ndex.html

\section{Acknowledgments:}

Ross Thompson, Katsky Venter, two anonymous reviewers, and the Zoology 502 seminar at the University of British Columbia read through an early draft and provided many insightful comments. We thank the editors of Conservation Ecology for helping to facilitate this discussion.

\section{LITERATURE CITED}

Albert, R., H. Jeong, and A.-L. Barabási. 2000. Attack and error tolerance in complex networks. Nature 406:387482.

Bawa, K., J. Rose, K. N. Ganeshaiah, N. Barve, M. C. Kiran, and R. Umashaanker. 2002. Assessing biodiversity from space: an example from the Western Ghats, India.
Conservation Ecology 6(2):7. [Online] URL: http://www.consecol.org/vol6/iss2/art7.

Berkes, F., and C. Folke, editors. 1998. Linking social and ecological systems: management practices and social mechanisms for building resilience. Cambridge University Press, Cambridge, UK.

Brown, J. H. 1995. Macroecology. University of Chicago Press, Chicago, Illinois, USA.

Carpenter, S. R. 1988. Transmission of variance through lake food webs. Pages 119-135 in S. R. Carpenter, editor. Complex interactions in lake communities. Springer-Verlag, New York, New York, USA.

Carpenter, S., W. Brock, and P. Hanson. 1999. Ecological and social dynamics in simple models of ecosystem management. Conservation Ecology 3(2):4. [Online] URL: http://www.consecol.org/vol3/iss2/art4.

Costanza, R., O. Segura, and J. Martinez-Alier. 1996. Integrated envisioning, analysis, and implementation of a sustainable and desirable society. Pages 1-16 in R. Costanza, O. Segura, and J. Martinez-Alier, editors. Getting down to earth: practical applications of ecological economics. Island Press, Washington, D.C., USA.

de la Mare, W. K. 1998. Tidier fisheries management requires a new MOP (management-oriented paradigm). Reviews in Fish Biology and Fisheries 8:349-356.

Dobson, A., A. Bradshaw, and A. Baker. 1997. Hopes for the future: restoration ecology and conservation biology. Science 277:515- 525.

Dunne, J. A., R. J. Williams, and N. D. Martinez. $2002 a$. Food-web structure and network theory: the role of connectance and size. Proceedings of the National Academy of Sciences of the United States of America 99:1291712922.

Dunne, J. A., R. J. Williams, and N. D. Martinez. $2002 b$. Network structure and biodiversity loss in food webs: robustness increases with connectance. Ecology Letters 5:558-567.

Franklin, J. F. 1989. Importance and justification of longterm studies in ecology. Pages 3-19 in G. E. Likens, editor. Long-term studies in ecology: approaches and alternatives. Springer-Verlag, New York, New York, USA.

Gass, C. L. 2002. Introduction to the special feature: educating for integration and sustainability. Conservation $\begin{array}{llll}\text { Ecology } & \mathbf{5}(2): 31 . & \text { [Online] URL: }\end{array}$ http://www.consecol.org/vol5/iss2/art31. 
Graham, M. H., P. K. Dayton, and M. A. Hixon, editors. 2002. Paradigms in ecology: past, present and future. Ecology 83(6):1479-1552.

Gunderson, L. H., and C. S. Holling. 2002. Panarchy: understanding transformations in human and natural systems. Island Press, Washington, D.C., USA.

Harte, J. 2002. Towards a synthesis of the Newtonian and Darwinian worldviews. Physics Today 55(10):29-34.

Harte, J., and A. P. Kinzig. 1997. On the implications of species-area relationships for endemism, spatial turnover, and food web patterns. Oikos 80:417-427.

Harte, J., T. Blackburn, and A. Ostling. 2001 Selfsimilarity and the relationship between abundance and range size. American Naturalist 157:374-386.

Hellmann, J. J., S. B. Weiss, J. F. McLaughlin, C. L. Boggs, P. R. Ehrlich, A. E. Launer, and D. D. Murphy. 2003. Do hypotheses from short-term studies hold in the long term? An empirical test. Ecological Entomology 28:7484.

Hilborn, R., and C. J. Walters. 1992. Quantitative fisheries stock assessment: choice, dynamics and uncertainty. Chapman and Hall, New York, New York, USA.

Holling, C. S., editor. 1978. Adaptive environmental assessment and management. Institute of Resource Ecology, University of British Columbia, Vancouver, Canada.

Holling, C. S. 1992. Cross-scale morphology, geometry, and dynamics of ecosystems. Ecological Monographs 62:447-502.

Holling, C. S. 1998. Two cultures of ecology. Conservation Ecology 2(2):4. [Online] URL: http://www.consecol.org/vol2/iss2/art4.

Holling, C. S., and C. R. Allen. 2002. Adaptive inference for distinguishing credible from incredible patterns in nature. Ecosystems 5:319-328.

IPCC (Intergovernmental Panel on Climate Change). 2001. Summary for policy makers, the third assessment report of the IPCC Working Group I. Cambridge University Press, Cambridge, UK.

Jordano, P., J. Bascompte, and J. M. Olesen. 2003. Invariant properties in coevolutionary networks of plantanimal interactions. Ecology Letters 6:69-81.

Kareiva, P. 1994. Space: the final frontier for ecological theory. Ecology 75:2.

Krawchuk, M. A., and P. D. Taylor. 2003. Changing importance of habitat structure across multiple spatial scales for three species of insects. Oikos 103:153-161.

Kuhn, T. S. 1962. The structure of scientific revolutions. University of Chicago Press, Chicago, Illinois, USA.

Lawton, J. H. 1999. Are there general laws in ecology? Oikos 84:177-192.

Levin, S. A. 1992. The problem of pattern and scale in ecology. Ecology 73(6):1943-1967.

Likens, G. E., editor. 1989. Long-term studies in ecology: approaches and alternatives. Springer-Verlag, New York, New York, USA.

Likens, G. E. 1992. The ecosystem approach: its use and abuse. Ecology Institute, Oldendorf-Luhe, Germany.

MacArthur, R. H., and R. Levins. 1964. Competition, habitat selection, and character displacement in a patchy environment. Proceedings of the National Academy of Sciences of the United States of America 51(6):1207-1210.

Magnuson, J. J. 1990. Long-term ecological research and the invisible present: uncovering the processes hidden because they occur slowly or because effects lag years behind causes. Bioscience 40:495-501.

McCullagh, P., and J. A. Nelder. 1989. Generalized linear models. Chapman and Hall, London, UK.

McIntosh, R. P. 1985. The background of ecology: concept and theory. Cambridge University Press, Cambridge, UK.

Mikkelson, G. M. 1997. Methods and metaphors in community ecology: the problem of defining stability. Perspectives on Science 5:481-498.

Mora, C., P. M. Chittaro, P. F, Sale, J. P. Kritzer, and S. A. Ludsin. 2003. Patterns and processes in reef fish diversity. Nature 421:933-936.

O'Connor, R. J. 2000. Why ecology lags behind biology. The Scientist 14(20):35.

Parmesan, C., and G. Yohe. 2003. A globally coherent fingerprint of climate change impacts across natural systems. Nature 421:37-42.

Perrings, C., K. Maler, C. Folke, C. S. Holling, and B. Jansson, editors. 1995. Biodiversity loss: economic and ecological issues. Cambridge University Press, Cambridge, UK. 
Peters, R. H. 1991. A critique for ecology. Cambridge University Press, Cambridge, UK.

Peterson, G., S. Pope, G. A. De Leo, M. A. Janssen, J. R. Malcolm, J. M. Parody, G. Hood, and M. North. 1997. Ecology, ethics, and advocacy. Conservation Ecology 1(1):17. [Online] URL: http://www.consecol.org/vol1/iss1/art17.

Raudenbush, S. W., and A. S. Bryk. 2002. Hierarchical linear models: applications and data analysis methods. Sage Publications, London, UK.

Real, L. A., and J. H. Brown, editors. 1991. Foundations of ecology: classic papers with commentaries. University of Chicago Press, Chicago, Illinois, USA.

Ritchie, M. E., and H. Olff. 1999. Spatial scaling laws yield a synthetic theory of biodiversity. Nature 400:557560 .

Root, T. L., J. T. Price, K. R. Hall, S. H. Schneider, C. Rosenzweig, and J. A. Pounds. 2003. Fingerprints of global warming on wild animals and plants. Nature 421:5760.

Sagoff, M. 1985. Fact and value in environmental science. Environmental Ethics 7(2):99-116.

Sainsbury, K. J., A. E. Punt, and A. D. M. Smith. 2000. Design and operational management strategies for achieving fishery ecosystem objectives. ICES Journal of Marine Science 57:731-741.

Shrader-Frechette, K. S., and E. D. McCoy. 1993. Method in ecology: strategies for conservation. Cambridge University Press, Cambridge, UK.

Shurin, J., S. Gergel., D. Kaufman, D. Post, E. Seabloom, and J. Williams. 2001. In defense of ecology. The Scientist 15(2):6.

Soulé, M. E., and K. A. Kohm. 1989. Research priorities for conservation biology. Island Press, Washington, D.C., USA.

Soulé, M. E., and G. H. Orians, editors. 2001. Conservation biology: research priorities for the next decade. Island Press, Washington, D.C., USA.

Srivastava, D. S. 2002. The role of conservation in expanding biodiversity research. Oikos 98(2):351-360.

Srivastava, D. S., and J. H. Lawton. 1998. Why more productive sites have more species: an experimental test of theory using tree-hole communities. American Naturalist
152:510-529.

Strayer, D., J. S. Glitzenstein, C. G. Jones, J. Kolasa, G. E. Likens, M. J. McDonnell, G. G. Parker, and S. T. A. Pickett. 1986. Long-term ecological studies: an illustrated account of their design, operation, and importance to ecology. Occasional Publication of the Institute of Ecosystem Studies, Number 2. Institute of Ecosystem Studies, Millbrook, New York, USA.

Strogatz, S. H. 2001. Exploring complex networks. Nature 410:268-276.

Tischendorf, L., and L. Fahrig. 2000. On the usage and measurement of landscape connectivity. Oikos 90:7-19.

Todd, B., and P. H. Kourtz. 1991. Predicting the daily occurrence of people-caused forest fires. Petawawa National Forestry Institute Information Report PI-X-103. Forestry Canada, Petawawa National Forestry Institute, Chalk River, Canada.

Turner, M. G., R. V. O'Neill, and R. H. Gardner. 2001. Landscape ecology in theory and practice: pattern and process. Springer-Verlag, New York, New York, USA.

Walker, B., S. Carpenter, J. Andries, N. Abel, G. Cumming, M. Janssen, L. Lebel, J. Norberg, G. D. Peterson, and R. Pritchard. 2002. Resilience management in social-ecological systems: a working hypothesis for a participatory approach. Conservation Ecology 6:14. [Online] URL: http://www.consecol.org/vol6/iss1/art14.

Walters, C. J. 1986. Adaptive management of renewable resources. Macmillan, New York, New York, USA.

West, G. B., J. H. Brown, and B. J. Enquist. 1997. A general model for the origin of allometric scaling laws in biology. Science 276:122-126.

Westoby, M. 1997. What does "ecology' mean? Trends in Ecology and Evolution. 12(4):166.

Wiens, J. A. 1989. Spatial scaling in ecology. Functional Ecology 3:385-397.

Williams, R. J., and N.D. Martinez. 2000. Simple rules yield complex food webs. Nature 404:180-183.

Yan, N. D., W. Keller, N. M. Scully, D. R. S. Lean, and P. J. Dillon. 1996. Increased UV-B penetration in a lake owing to drought-induced acidification. Nature 381:141143. 